\title{
Case report: revision of a nasal scar after a vehicle accident
}

\begin{abstract}
A 30years old male patient presented with a nasal scar at the junction between the columella and the nasal tip, after one year of exposure to a vehicle accident with an inappropriate suturing, I found that the scar repositioning is the best technique for this patient, so I decided to do external approach Rhinoplasty with changing the position of the new scar to a lower position.
\end{abstract}

Keywords: scar revision, external approach rhinoplasty, facial wounds
Volume 6 Issue $6-2017$

\section{Menwal Harb}

ENT Specialist American Crescent Health Care Center, UAE

Correspondence: Menwal Harb ENT Specialist Arab Board Certified Syria American Crescent Health Care Center Abu Dhabi, UAE, Tel 0097I528046377, Email menwalh@yahoo.com

Received: November 26, 2016 | Published: April 21, 2017

\section{Introduction}

The healing of the wound results in a scar, the appearance of the scar depends on the wounding mechanism, wound location, wound tension, initial treatment, infection, and dehiscence. ${ }^{1}$ Successful scar revision begins with a precise analysis of both the scar and the patient expectations. The surgeon should educate the patient on the true realistic goal of surgery, which is to modify the scar to a point of maximized camouflage within the natural shadows, lines and borders that exist within the head and neck. ${ }^{2}$

\section{Case presentation}

A 30years old male patient presented with a nasal scar at the junction between the columella and nasal tip at the left side of the nose, after one year of a vehicle accident, with a left side nasal obstruction. No other complaints, no medical history, no surgical history.

\section{The physical examination}

An external nasal scar, deviation of the nasal axis to the right side, left septal deviation, the remainder examination is within normal. The goal is to remove the scar and improve the nasal breathing.

\section{The plan}

External approach rhinoplasty, which is discussed with the patient and greed.

\section{The surgical technique}

The first step is the scar removal, after that I completed the surgery as a traditional external approach rhinoplasty with septoplaty, hump grasping, bilateral lateral osteotomies, tip plasty, then I retracted the nasal skin and stitched it at the columella at the lowest possible position without any tension at the sutures and wound edges, which was at the middle of the columellar length, then I trimmed the skin edges to create the nostrils edges. The result and follow up: The stitches and the nasal splint are removed one week after the surgery, and the patient returned to his normal daily activities after two weeks. The follow up after six months: The patient is fully satisfied of the result, functionally and aesthetically, (Figure 1). The techniques of scar revision are classified in (Table 1).

\section{Discussion}

Causes of unfavorable scar formation can be genetic, iatrogenic, circumstantial, or idiopathic. ${ }^{3}$ In our case I chose the scar repositioning technique, and discussed with the patient, that I will do an external approach rhinoplasty to extend the skin and make the scar in a lower position without any unnecessary skin incisions, and to correct the nasal axis deviation and the septal deviation.

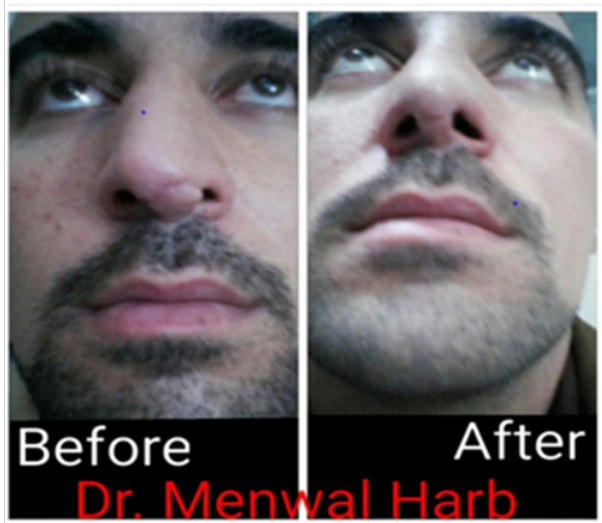

Figure I The patient before and after the surgery.

Table I The techniques of scar revision [2]

Excisional Techniques
Incision Placement
Fusiform Excision
Shave Excision
Scar Repositioning
Serial Partial Excision
Irregularization Techniques
Z-plasty
W-plasty
Geometric Broken-line Closure
Dermabrasion, Laser Resurfacing
Fillers
Adjunctive Techniques
Steroids
Dressings, Medications
Cosmetics

\section{Conclusion}

The best technique of scar revision is the technique that gives us the best camouflage, by doing the incisions parallel to or in relaxed skin tension lines, at the junction of facial aesthetic units, within margins of orifices, or at the edge of hair line, and staged procedures are often necessary to accomplish the optimal result. 


\section{Acknowledgments}

None.

\section{Conflicts of interest}

Author declares there are no conflicts of interest.

\section{Funding}

None.

\section{References}

1. Bailey Byron J, Johnson Jonas T, Shawn Newlands D. Head \& Neck Surgery-Otolaryngology. (4th edn), California, USA. 2006.

2. Paul Flint W, Bruce Haughey H, Valerie Lund J, et al. Cummings Otolaryngology-Head \& Neck Surgery, $\left(5^{\text {th }}\right.$ edn $) .2011$.

3. Garg S, Dahiya N, Gupta S. Surgical scar revision: an overview. J Cutan Aesthet Surg. 2001;7(1):3-13. 